\title{
Liquid chromatography-mass spectrometry analysis of cationic aniline dyes from the Technical University of Dresden Historical Collection of Dyes
}

Journal of Chemical Research 2020, Vol. 44(5-6) 326-335 (C) The Author(s) 2020 (c) (i)

Article reuse guidelines: sagepub.com/journals-permissions DOI: $10.1177 / 1747519819901103$

journals.sagepub.com/home/chl

(S)AGE

\author{
Michael John Plater' (D, Andrea Raab' and Horst Hartmann²
}

\begin{abstract}
Liquid chromatography-mass spectrometry has been used to analyse a range of cationic aniline dyes from the 19th century. Mauveine from the Chandler museum is used as a standard for comparison. This consists of a typical W. $\mathrm{H}$. Perkin mixture of mauveine A and B. Mauveine from a historic collection in Dresden is different and consists of mainly mauveine $A$ and a monomethyl mauveine chromophore. Possible synthetic routes and its significance are discussed. Three samples of phenylated rosanilines have been analysed, and a list of 19 possible components compiled. An analysis by liquid chromatography-mass spectrometry works well on this complex mixture giving clear information on retention times and accurate mass molecular weights. Mono-, di- and triphenylrosanilines are present in two samples, and a third sample has mainly monophenylrosaniline. In each sample, a small amount of higher molecular weight homologues appear. The thin-layer chromatography plate, from left to right, has fuchsin or rosaniline then mono-, di- and triphenylrosaniline. The two spots on the right-hand side are blue, and the two spots on the left-hand side are red.
\end{abstract}

\section{Keywords}

aniline blue, fuchsin, mauveine, rosaniline, triphenylrosaniline

Date received: 12 November 2019; accepted: 24 December 2019

Liquid chromatography-mass spectrometry analysis of historical triphenylrosaniline (aniline blue) reveals 19 components.

\section{Introduction}

The Faculty of Chemistry and Food Chemistry of the Technical University of Dresden administers a Historical Collection of Dyes. ${ }^{1}$ This collection is one of the oldest and largest collections of its kind and contains 8000 trade samples of synthetic dyes, coal-tar colours or aniline colours, in original bottles and cans made by approximately 80 manufacturers. It also houses more than 500 samples of natural dyes. The collection of dyes has nearly 300 historical triarylmethane dyes as well as a sample of mauveine given by W. H. Perkin. Mauve was discovered by Perkin ${ }^{2}$ in London in 1856 followed by Verguin's ${ }^{3}$ discovery of fuchsin or rosaniline in France in 1859 (Figure 1). This dye is sometimes called aniline red, rosaniline or magenta. Girard and de Laire $^{4}$ (Figure S1) discovered triphenylrosaniline by heating fuchsin or rosaniline with aniline in 1861. This insoluble blue dye was called bleu de Lyon or imperial violet. Hofmann played an important role in characterising rosaniline 2, and he showed that aniline blue $\mathbf{3}$ was a triphenylated rosaniline made by the displacement of ammonia with aniline.$^{5-7}$ Hofmann studied the synthesis of rosaniline using aniline prepared from indigo and pure benzene, and confirmed that pure aniline gave no rosaniline. Manufacturers had noticed that the oxidation of aniline of higher boiling point (containing more toluidine) gave higher yields of rosaniline. ${ }^{5}$ Hence, in these syntheses, as for mauveine, the toluidine content of the aniline is essential for better yields and is likely to give a mixture of methylated chromophores. A range of different oxidants were developed. Verguin, of Messrs Renard Freres of Lyons, used $\mathrm{SnCl}_{4}{ }^{3}$ Perkin used $\mathrm{Hg}(\mathrm{II}),{ }^{8}$ and Medlock, ${ }^{9}$ Nicholson ${ }^{10}$ and Girard and de Laire ${ }^{11}$ used $\mathrm{As}_{2} \mathrm{O}_{3}$. A disadvantage of triphenylrosaniline for printing is its poor solubility. Nicholson overcame this problem by sulfonating

\footnotetext{
'Department of Chemistry, University of Aberdeen, Aberdeen, UK ${ }^{2}$ Historische Farbstoffsammlung, Technische Universität Dresden, Dresden, Germany
}

\section{Corresponding author:}

Michael John Plater, Department of Chemistry, University of Aberdeen, Meston Walk, Aberdeen AB24 3UE, UK.

Email: m.j.plater@abdn.ac.uk 


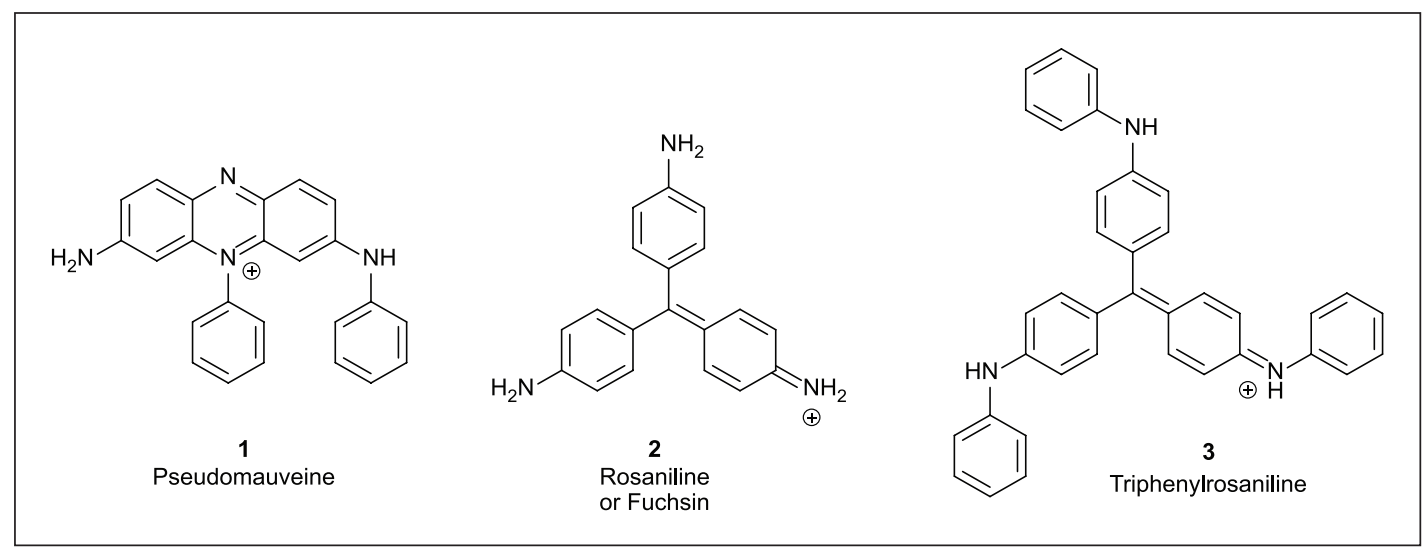

Figure I. The parent structures of mauveine, fuchsin and triphenylrosaniline.

it in sulfuric acid giving two sulfonated derivatives, a mono- and a tri- which are known as Nicholson's blue and Nicholson's soluble blue ${ }^{5,12}$ (Figure S1). Owing to the formation of this class of cationic dye from aniline and variable amounts of toluidine, a liquid chromatography-mass spectrometry (LC-MS) study on some early samples has been performed to examine the product composition.

\section{Discussion}

A sample of mauveine and three dyes from the Technical University of Dresden Historical Collection of Dyes were analysed by LC-MS. A standard mauveine from the Chandler museum in New York was analysed (see Figure 2 and Table 1). ${ }^{13}$ A photograph is shown in the Supplemental Material (Figure S2). Perkin gave this mauveine to $\mathrm{C}$. Chandler in 1906, and he was the recipient of the first American Chemical Society (ACS) Perkin Medal, which is still awarded today. ${ }^{14}$ Perkin received a tea set and embossed silver tray from his American friends in commemoration of the 50th anniversary of his discovery of the dye mauve, New York, 6 October 1906 (Figure S3). ${ }^{15}$ The chart has two scales on the vertical axis, one for the ultraviolet (UV) absorption at $550 \mathrm{~nm}$ in milli-Absorption Units (mAU) and one for the mass spectrometer in Electro Spray Mass Spectrometer (ES-MS) counts. The horizontal axis has the retention time, as the mauveine is eluted with gradient elution from a reverse phase silica column. This separates compounds by size and works well for cationic chromophores, which differ in size by one methyl group $\left(\mathrm{CH}_{2}\right) .{ }^{16}$ This sample is typical of the mauveine which $\mathrm{W}$. $\mathrm{H}$. Perkin produced by a unique manufacturing process and is rich in mauveine $\mathrm{A}(391,37 \%)$ and $\mathrm{B}(405,30 \%) .{ }^{16}$ Figure 3 shows the structure of some typical mauveine chromophores. A previous analysis was done by nuclear magnetic resonance (NMR) ${ }^{17}$ and high-performance liquid chromatography (HPLC). ${ }^{18,19}$ The composition is similar to that of the mauveine stored in London, Manchester, Bradford and Sudbury. ${ }^{20-24}$ This is different to the mauveine which is obtained by Perkins patented method, which has become the source of much research suggesting that Perkin carried out research and development to improve the method for making mauveine but kept it secret from potential competitors. ${ }^{25}$

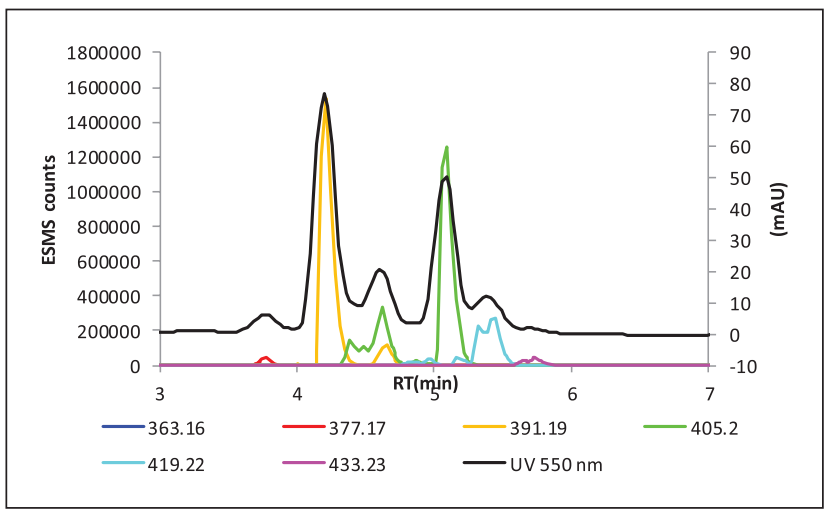

Figure 2. A reference sample of mauveine.

LC-MS chart of mauveine from the Chandler museum, New York. Extracted ion chromatograms with UV absorption at $550 \mathrm{~nm}$.

Table I. Relative peak areas for Figure 2.

\begin{tabular}{|c|c|c|c|c|c|c|}
\hline $\mathrm{min} / \mathrm{m} / \mathrm{z}$ & 363 & 377 & 391 & 405 & 419 & 433 \\
\hline 3.8 & & 1.0 & & & & \\
\hline 4.2 & & & 37.2 & & & \\
\hline 4.4 & & & & 3.3 & & \\
\hline 4.5 & & & & 2.3 & & \\
\hline 4.6 & & & 3.0 & 7.4 & & \\
\hline 5.1 & & & & 30.0 & & \\
\hline 5.2 & & & & & 1.0 & \\
\hline 5.3 & & & & & 6.1 & \\
\hline 5.4 & & & & & 5.4 & \\
\hline
\end{tabular}

Figure 4 and Table 2 show data from the LC-MS analysis of mauveine from the Technical University of Dresden. W. H. Perkin visited here in the 19th century. A picture of the bottle (Figure S4), a card for it (Figure S5), with the names 'violet au bichromate' and 'violet pate', and some skeins from Perkin (Figure S6) are shown in the Supplemental Material. This mauveine is dominated by a monomethyl mauveine $(377,13 \%)$ and mauveine A (393, $28 \%$ ) with very little mauveine B present. The monomethyl mauveine chromophores have been suggested as mauveine $\mathrm{C} 25 \mathrm{a}$ or $\mathrm{C} 25 \mathrm{~b} .{ }^{19}$ This mauveine analysis came as a surprise because all previous samples of Perkin's mauveine are rich in mauveine $\mathrm{A}$ and $\mathrm{B}$, and were made by a unique manufacturing process. ${ }^{16}$ This sample could 


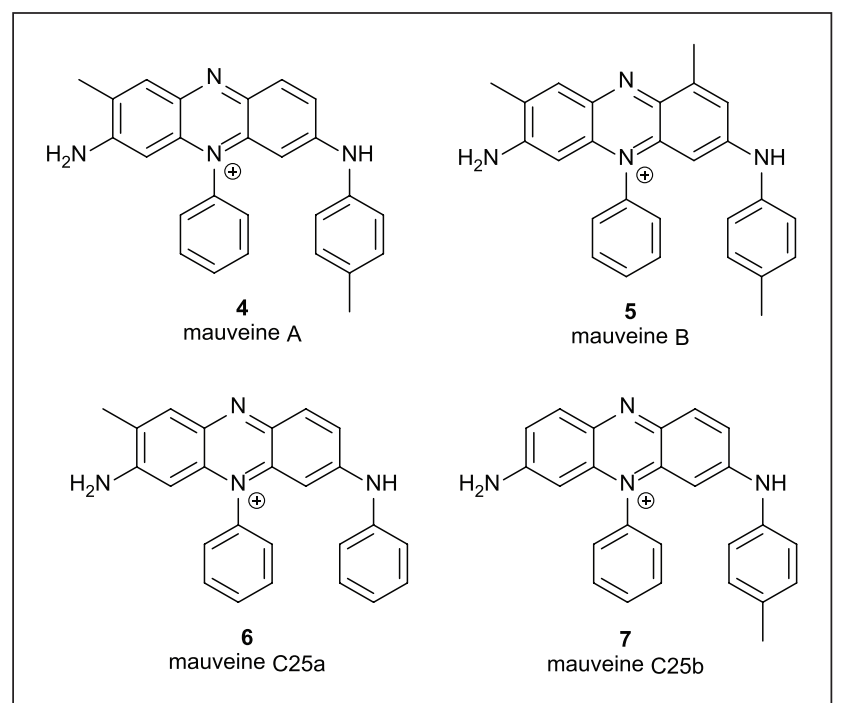

Figure 3. The structures of some mauveine chromophores.

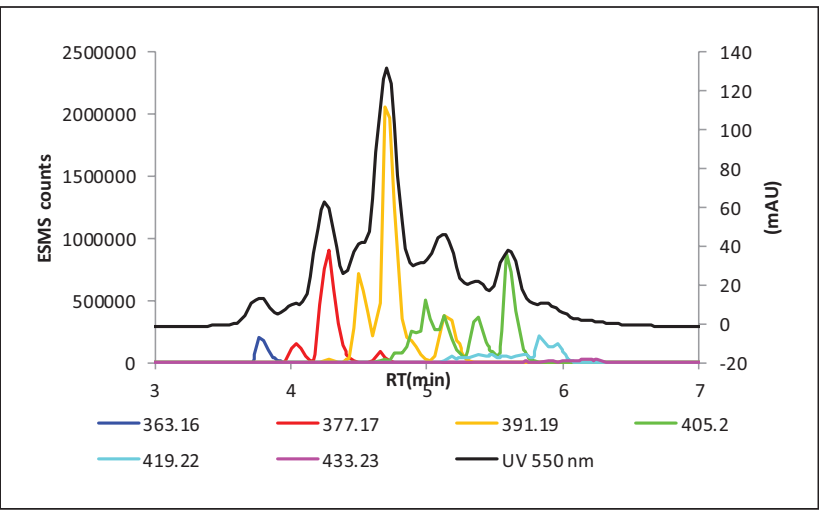

Figure 4. LC-MS chart of mauveine from the Technical University of Dresden.

Extracted ion chromatograms with UV absorption at $550 \mathrm{~nm}$.

be the first example of Perkin's ${ }^{2}$ mauveine which was made by his patented method of 1856 in which the toluidine content has been increased above $10 \%$. The percentage of toluidine in the aniline which is oxidised controls the products which form. Oxidation of aniline containing $10 \%$ toluidine gives pseudomauveine and a monomethyl mauveine, but as the percentage of toluidine increases, more methylated mauveine chromophores form. ${ }^{15}$ However, this particular composition containing a monomethyl mauveine, mauveine A and little mauveine B was not observed. Mauveine B forms efficiently like mauveine A, and we would have expected more mauveine B to form and others. ${ }^{19}$ A similar match to this sample was only observed when $p$-toluidine was replaced with $N$-tertbutyl- $p$-toluidine in the synthesis, and the front fraction from a column was collected. ${ }^{26}$ Figure 5 and Table 3 show data from the analysis of a rare plate 6 Victorian stamp. ${ }^{27}$ This mauveine may have been made from oxidising aniline containing a low percentage of toluidine (10\%-15\%). Since it is different from Perkin's mauveine, and more similar to Schunck's ${ }^{28}$ or Caro's mauveine, ${ }^{29}$ it has been suggested that Caro would have made it. ${ }^{30}$ However, the
Table 2. Relative peak areas for Figure 4.

\begin{tabular}{llrrrrr}
\hline $\mathrm{min} / \mathrm{m} / \mathrm{z}$ & 363 & 377 & 391 & 405 & 419 & 433 \\
\hline 3.8 & 2.4 & & & & \\
4.0 & & 1.8 & & & \\
4.3 & & 13.2 & & & \\
4.5 & & & 9.6 & & \\
4.7 & & & 28.1 & & \\
4.8 & & & & 1.1 & \\
4.9 & & & & 1.8 & \\
5.0 & & & & 6.1 & \\
5.1 & & & & 4.4 & \\
5.2 & & & 6.3 & & \\
5.4 & & & & 5.4 & \\
5.6 & & & & 10.3 & \\
5.8 & & & & & 2.3 \\
6.0 & & & & & 1.7 \\
\hline
\end{tabular}

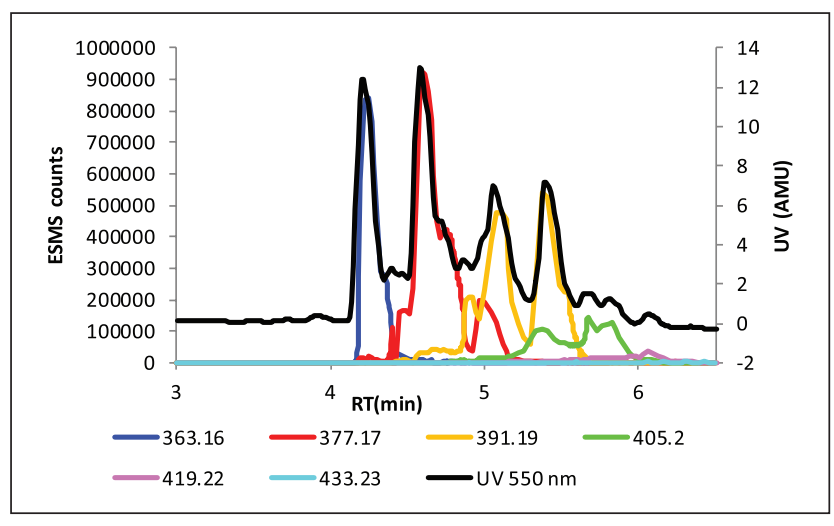

Figure 5. LC-MS chart of mauveine from a plate 6 Victorian $6 \mathrm{~d}$ stamp. $^{27}$

Extracted ion chromatograms with UV absorption at $550 \mathrm{~nm}$.

discovery of mauveine from Perkin at the Technical University of Dresden, which might have come from oxidising aniline low in toluidines, suggests that the mauveine on the stamp could have been made by Perkin. Perkin has stated, though, that he made mauveine from toluidine-rich mixtures of aniline as the yield is higher.

\section{Triphenylrosaniline: Girard and de Laire's bleu de Lyon or imperial violet}

Three samples of historic dye from the Dresden archive were provided to analyse and characterise by LC-MS.,5 Samples 1 and 2 were blue, and sample 3 was red. A thin-layer chromatography (TLC) plate of samples 1 and 2 showed two weaker red spots and higher up the plate two blue spots (Figure 6). These are identified shortly by LC-MS.

The dyes were analysed by LC-MS under conditions of gradient elution that are used for the analysis of mauveine samples. The separation and analysis work very well. The results from the analysis of sample 1 are shown in Figure 7, with Tables 4-7; for sample 2, Figure 8 with 
Tables 8-11; and for sample 3, Figure 9 with Tables $12-$ 15 . Table 16 is a list of the proposed dyes, which are present. The chart in Figures 7-9 shows four groups of dyes which have been separated by LC-MS counted from left to right. The mass spectral data for each group are shown as Groups 1-4 under each chart and are colour-coded. The same colours are repeated for each group, representing different molecular weights, because not enough different colours were available. The relative peak area for each group is shown in the tables. The four groups of compounds are mainly rosaniline, mono-, di- and triphenylrosaniline. Each of these is a mixture because the rosaniline starting material is made from aniline rich in toluidine and has four possible homologues. ${ }^{32}$

\section{Samples I and 2}

In Figure 7 or 8, Group 1, there are four compounds of molecular weights 288-302-316-330. Each differs by a mass of $14\left(\mathrm{CH}_{2}\right)$ corresponding to one methyl group. The proposed structures of these compounds $\mathbf{2 , 8 - 1 0}$ are drawn in Table 16. These are small quantities of fuchsin or rosaniline remaining in the starting material, which did not react with aniline. Sample 2 has more residual fuchsin compared to sample 1. In Figure 7 or 8, Group 2, there are five compounds of molecular weights 364-378-392406-420. The proposed structures of these compounds 11-15 are drawn in Table 16. They are formed from reacting one mole of an aniline with rosaniline, so the reaction did not go to completion. Compound $\mathbf{1 5}$ requires aniline and toluidine to react with rosaniline. The toluidines must only be present in small amounts in the aniline used for the synthesis. In Figure 7 or 8, Group 3, there are five compounds of molecular weights 440-454-468-482496. The proposed structures of these compounds $\mathbf{3}$,
16-19 are drawn in Table 16. Compounds 3 and 16-18 are diphenylrosanilines, which have not been reported before. Compound 19 requires aniline and toluidine to react with rosaniline. Their presence indicates that the reaction did not go to completion. They are assigned as

Table 3. Relative peak areas for Figure 5.

\begin{tabular}{llrrrr}
\hline $\mathrm{min} / \mathrm{m} / \mathrm{z}$ & 363 & 377 & 391 & 405 & 419 \\
\hline 4.2 & 19.2 & & & & \\
4.5 & & 2.5 & & & \\
4.6 & & 22.2 & & & \\
4.8 & & 6.5 & 1.7 & & \\
5.0 & & 4.9 & 2.3 & & \\
5.1 & & & 12.7 & & \\
5.4 & & & 11.9 & 2.7 & \\
5.5 & & & 3.2 & 1.4 & \\
5.7 & & & & 2.3 & \\
5.8 & & & & 2.9 & \\
6.1 & & & & & 2.1 \\
\hline
\end{tabular}

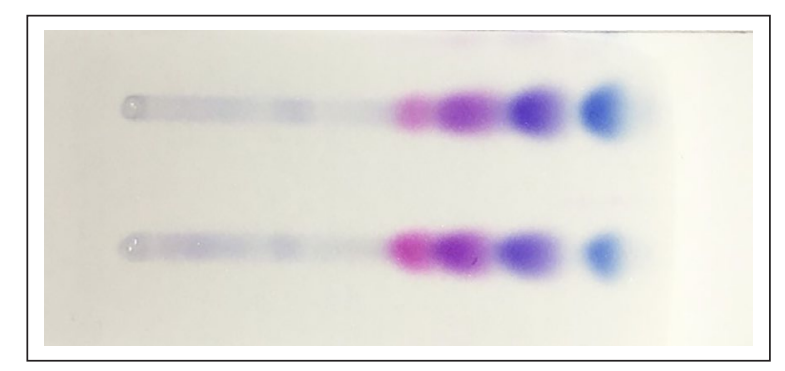

Figure 6. TLC analysis of sample I (top) and sample 2 (bottom) of triphenylrosaniline eluted with secBuOH/EtOAc/ $\mathrm{H}_{2} \mathrm{O} / \mathrm{HOAc}(60: 30: 9.5: 0.5)$.

Only the two spots to the right are blue.

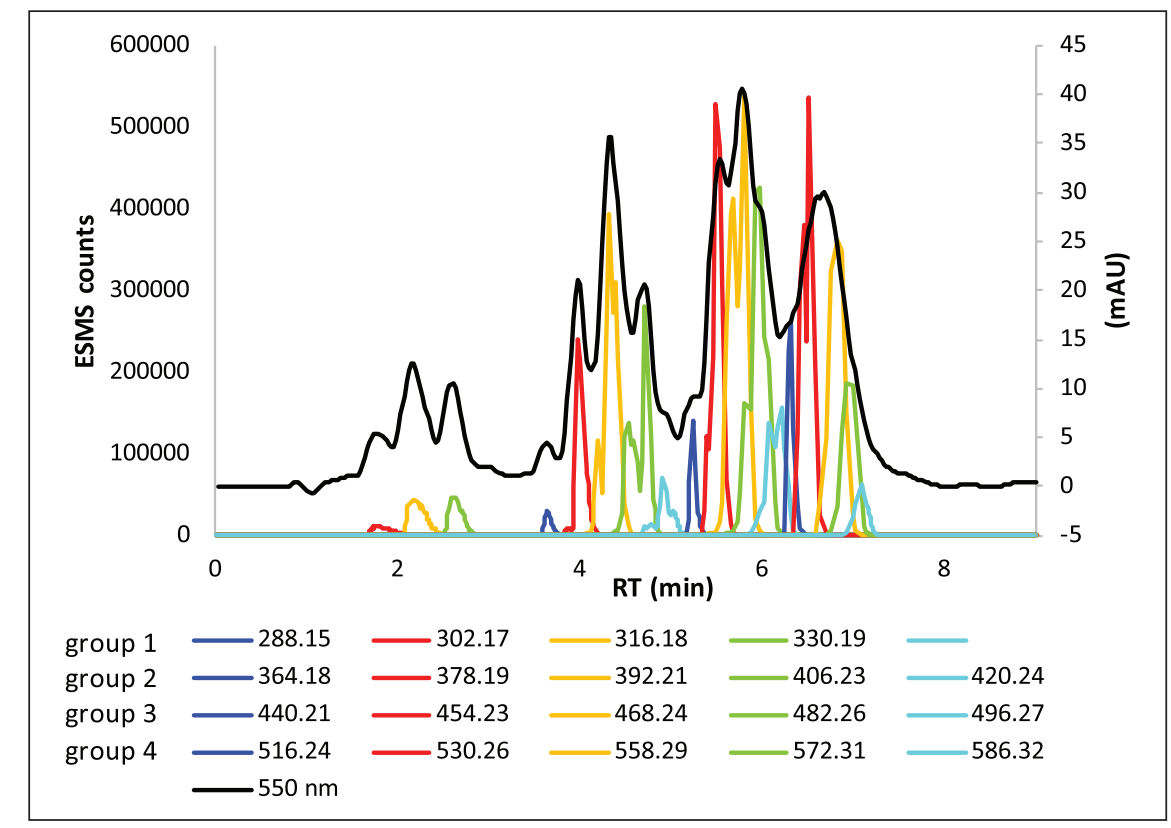

Figure 7. Sample I LC-MS chart of the historic dyes formed from the condensation of rosaniline with aniline. Extracted ion chromatograms with UV absorption at $550 \mathrm{~nm}$. There are four groups of compounds with one colour representing a different molecular weight for each of the groups. The groups are counted from left to right. 
Table 4. Group I in Figure 7.

\begin{tabular}{lllll}
\hline $\mathrm{Min} / \mathrm{m} / \mathrm{z}$ & 288 & 302 & 316 & 330 \\
\hline 1.5 & 0.1 & & & \\
1.7 & & 0.4 & & \\
1.9 & & 0.3 & & \\
2.1 & & & 1.3 & \\
2.3 & & & 0.5 & \\
2.6 & & & & 1.5 \\
\hline
\end{tabular}

Table 5. Group 2 in Figure 7.

\begin{tabular}{llllll}
\hline $\mathrm{Min} / \mathrm{m} / \mathrm{z}$ & 364 & 378 & 392 & 406 & 420 \\
\hline 3.6 & 0.5 & & & & \\
3.9 & & 0.2 & & & \\
4.0 & & 3.4 & & & \\
4.1 & & 0.3 & & & \\
4.2 & & & 1.1 & & \\
4.4 & & & 7.5 & 0.2 & \\
4.5 & & & & 2.7 & \\
4.7 & & & & 3.8 & \\
4.8 & & & & & 0.6 \\
4.9 & & & & & 1.0 \\
5.1 & & & & & 0.3 \\
\hline
\end{tabular}

Table 6. Group 3 in Figure 7.

\begin{tabular}{llllll}
\hline $\mathrm{Min} / \mathrm{m} / \mathrm{z}$ & 440 & 454 & 468 & 482 & 496 \\
\hline 5.2 & 1.5 & & & & \\
5.5 & & 9.1 & & & \\
5.7 & & & 6.1 & & \\
5.8 & & & 9.3 & 2.4 & \\
5.9 & & & & 6.7 & \\
6.0 & & & & & 0.6 \\
6.1 & & & & 3.4 & 2.0 \\
6.2 & & & & & 2.4 \\
6.3 & & & & & 0.3 \\
\hline
\end{tabular}

Table 7. Group 4 in Figure 7.

\begin{tabular}{llllll}
\hline $\mathrm{Min} / \mathrm{m} / \mathrm{z}$ & 516 & 530 & 558 & 572 & 586 \\
\hline 6.3 & 2.9 & & & & \\
6.4 & & 5.0 & & & \\
6.5 & & 4.5 & & & \\
6.8 & & & 10.7 & & \\
7.0 & & & & 5.4 & \\
7.1 & & & & & 1.8 \\
\hline
\end{tabular}

the lower blue spot on the TLC plate. In Figure 7 or 8 , Group 4, there are five compounds of molecular weights 516-530-558-572-586. The proposed structures of these compounds 20-24 are drawn in Table 16. These are assigned as the uppermost blue spot on the TLC plate. Compounds 20-22 are triphenylrosanilines. A small amount of toluidine is required in the reacting aniline to give triarylrosanilines $\mathbf{2 3}$ and $\mathbf{2 4}$.

\section{Sample 3}

The same four groups of peaks appear here in sample 3, which were present in samples 1 and 2. In Figure 9, Group 1 , there are four compounds of molecular weights 288302-316-330. The proposed structures of these compounds 2, 8-10 are drawn in Table 16. There is very little fuchsin or rosaniline remaining in the starting material which did not react with aniline or it has been removed in a purification process. In Figure 9, Group 2, there are five compounds of molecular weights 364-378-392-406-420. The proposed structures of these compounds 11-15 are drawn in Table 16. They are formed from reacting one mole of aniline with rosaniline. Compound $\mathbf{1 5}$ requires a toluidine to react with rosaniline. The toluidines must only be present in small amounts in the aniline used for the synthesis, so this compound is a minor product. This compound is mainly phenylrosaniline $\mathbf{1 1}$ and presumably requires a careful reaction and purification process as the reaction gives mixtures. In Figure 9, Group 3, there are five compounds of molecular weights 440-454-468-482496. The proposed structures of these compounds 3, 16-19 are drawn in Table 16. Compounds $\mathbf{3}$ and 16-18 are diphenylrosanilines. A small amount of toluidine is required in the reacting aniline to give compound 19 . They appear as a trace of the lower blue spot on the TLC plate (not shown). In Figure 9, Group 4, there are four compounds of molecular weights 516-530-558-572. The proposed structures of these compounds 20-23 are drawn in Table 16. Compounds 20-22 are triphenylrosanilines. A small amount of toluidine is required in the reacting aniline to give compound 23. Groups 1, 3 and 4 are minor components of this mixture with Group 2 dominant. A synthesis of phenylrosaniline, called Regina Purple, has been reported by E. C. Nicholson, patented in 1862 , so this might be a rare sample from that synthesis of heating rosaniline acetate at 200$215^{\circ} \mathrm{C} .^{33}$ It would be difficult otherwise to control the reaction with such a high degree of selectivity.

\section{Interpretation}

Table 16 lists suggested structures for the products based on their accurate mass data. Most of the compounds differ in molecular structure by one methyl group, which is sufficient for them to be separated on a reverse phase silica column and characterised by ES-MS counts. Elution on a TLC plate with the Meth-Cohn and Smith ${ }^{17}$ eluent gives, from left to right, the four groups of spots, which correspond to the groups of compounds seen in the LC-MS (Figure 6). These are rosaniline (red), monophenylrosanilines (red/ purple), diphenylrosanilines (dark blue) and triphenylrosanilines (light blue). The order of elution of the spots is reversed on a reverse phase silica column from that on a TLC plate. On reverse phase silica, the separation is based on size, so a difference in size of one methyl group is sufficient for the compounds to separate from a large mixture. The diphenylrosanilines are a darker blue colour, and the triphenylrosanilines are a lighter turquoise blue colour. 


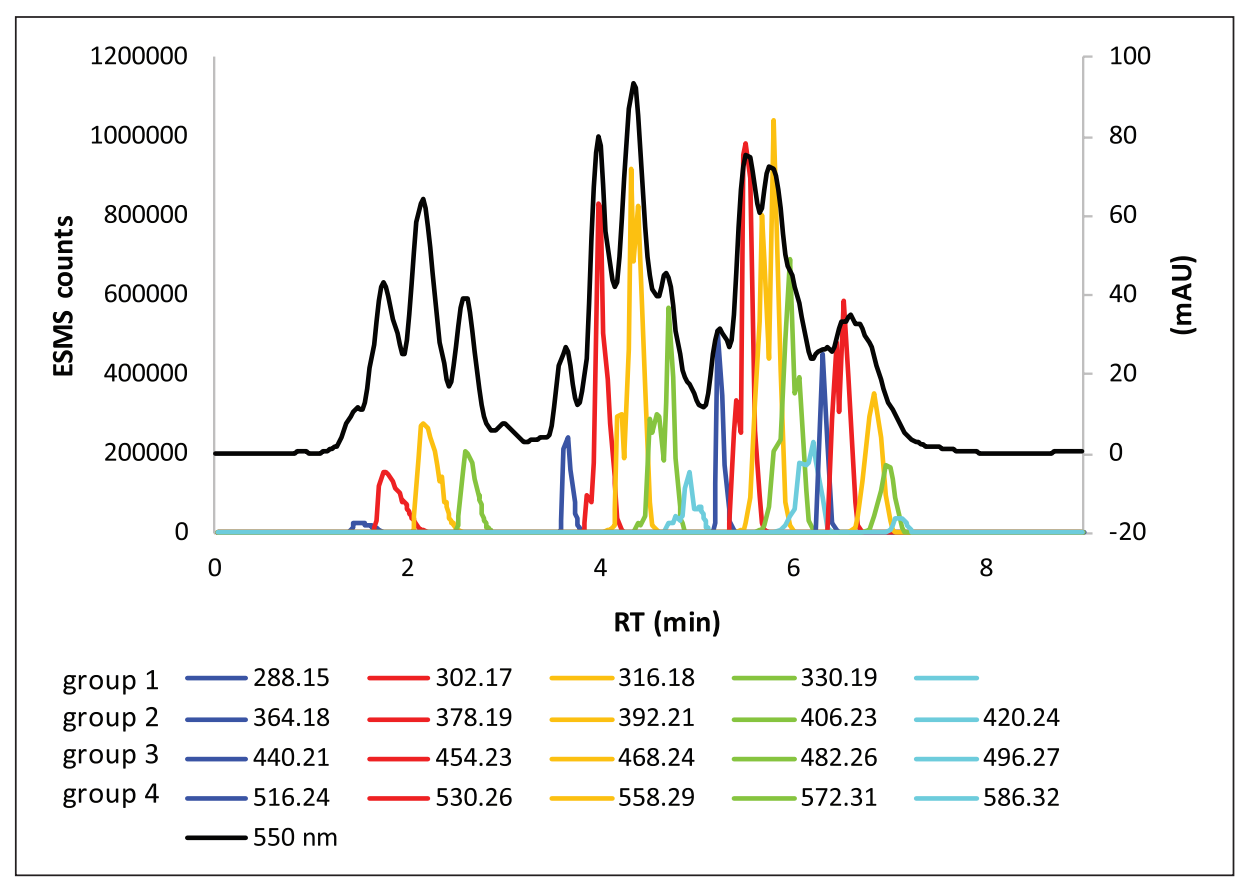

Figure 8. Sample 2 LC-MS chart of the historic dyes formed from the condensation of rosaniline with aniline. Extracted ion chromatograms with UV absorption at $550 \mathrm{~nm}$. There are four groups of compounds with one colour representing a different molecular weight for each of the groups. The groups are counted from left to right.

Table 8. Group I in Figure 8.

\begin{tabular}{lllll}
\hline $\mathrm{Min} / \mathrm{m} / \mathrm{z}$ & 288 & 302 & 316 & 330 \\
\hline 1.5 & 0.5 & & & \\
1.7 & & 1.9 & & \\
1.9 & & 1.1 & & \\
2.2 & & & 3.5 & \\
2.3 & & & 1.4 & 2.8 \\
2.6 & & & & \\
\hline
\end{tabular}

Table 9. Group 2 in Figure 8.

\begin{tabular}{llllll}
\hline $\mathrm{Min} / \mathrm{m} / \mathrm{z}$ & 364 & 378 & 392 & 406 & 420 \\
\hline 3.6 & 1.8 & & & & \\
3.9 & & 0.6 & & & \\
4.0 & & 5.5 & & & \\
4.1 & 2.1 & & & \\
4.2 & & & 2.5 & & \\
4.3 & & & 3.6 & & \\
4.4 & & & 6.0 & 0.1 & \\
4.5 & & & & 1.6 & \\
4.6 & & & & 2.0 & \\
4.7 & & & 3.8 & 0.1 \\
4.8 & & & & 0.2 \\
4.9 & & & & & 1.2 \\
5.0 & & & & & 0.4 \\
\hline
\end{tabular}

These studies show that this reaction on an industrial manufacturing scale did not go to completion, and the two different blue compounds would give different shades of blue as was reported. ${ }^{5}$ The synthesis involves a condensation of aniline with rosaniline. The central positive charge must activate each arylamine to nucleophilic attack, or the resonance form of an imine shown in Table 16 condenses with
Table 10. Group 3 in Figure 8.

\begin{tabular}{llllll}
\hline $\mathrm{Min} / \mathrm{m} / \mathrm{z}$ & 440 & 454 & 468 & 482 & 496 \\
\hline 5.2 & 3.0 & & & & \\
5.4 & & 2.5 & & & \\
5.7 & & & 7.8 & & \\
5.8 & & & 5.3 & 2.3 & \\
6.0 & & & & 5.1 & 0.5 \\
6.1 & & & & 2.1 & 1.5 \\
6.2 & & & & & 1.8 \\
\hline
\end{tabular}

Table II. Group 4 in Figure 8.

\begin{tabular}{llllll}
\hline $\mathrm{Min} / \mathrm{m} / \mathrm{z}$ & 516 & 530 & 558 & 572 & 586 \\
\hline 6.3 & 3.1 & & & & \\
6.4 & & 2.4 & & & \\
6.5 & & 4.3 & & & \\
6.8 & & & 4.9 & & \\
7.0 & & & & 2.3 & \\
7.1 & & & & & 0.5 \\
\hline
\end{tabular}

aniline. Either mechanism is likely to be similar in energy. It is not an oxidation reaction, so toluidines should have no preference to react over aniline as they do in oxidations to form mauveine or rosaniline. Hence, the main products, which are still mixtures, have a phenylamine as the outer unit since aniline low in toluidine was used. ${ }^{5}$ The thermal condensation of aniline hydrochloride in boiling aniline to make diphenylamine shows that the method can work even on unactivated anilines. ${ }^{34-36}$ Additional isomers not drawn here must still be possible, such as the condensation of compounds 8 or 9 with toluidine rather than aniline, but aniline was present to a big excess $(90 \%$ or more), so the products shown are likely to be the main ones from reaction 


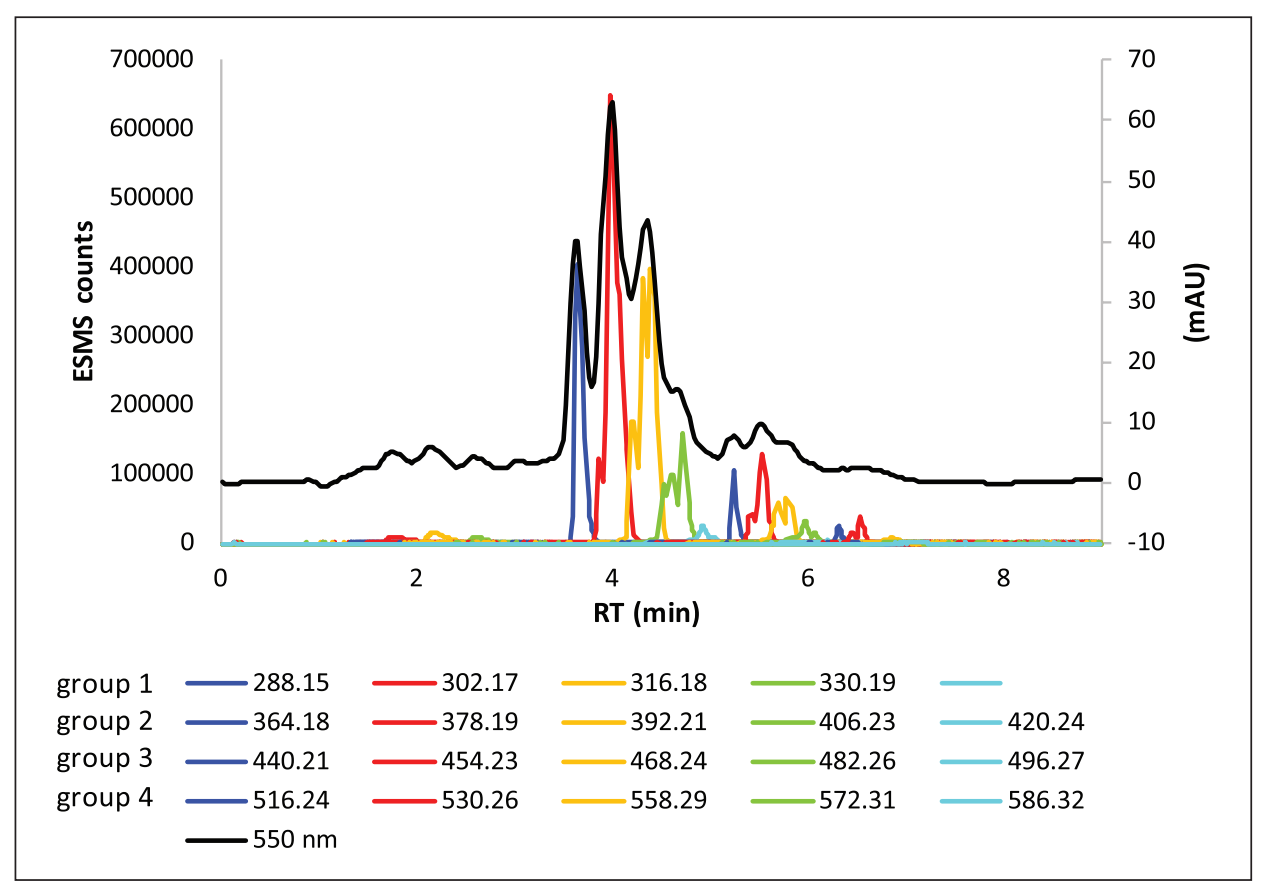

Figure 9. Sample 3 LC-MS chart of the historic dyes formed from the condensation of rosaniline with aniline. Extracted ion chromatograms with UV absorption at $550 \mathrm{~nm}$. There are four groups of compounds with one colour representing a different molecular weight for each of the groups. The groups are counted from left to right. In this sample, group 2 is dominant over the others.

Table I2. Group I in Figure 9.

\begin{tabular}{lllll}
\hline $\mathrm{Min} / \mathrm{m} / \mathrm{z}$ & 288 & 302 & 316 & 330 \\
\hline 1.5 & 0.2 & & & \\
1.7 & & 0.4 & & \\
1.9 & & 0.4 & & \\
2.2 & & & 0.6 & \\
2.3 & & & 0.4 & 0.5 \\
2.6 & & & & 0.5 \\
\hline
\end{tabular}

Table 13. Group 2 in Figure 9.

\begin{tabular}{lrrrrr}
\hline $\mathrm{Min} / \mathrm{m} / \mathrm{z}$ & 364 & 378 & 392 & 406 & 420 \\
\hline 3.6 & 13.8 & & & & \\
3.9 & & 3.2 & & & \\
4.0 & & 19.0 & & & \\
4.1 & 9.1 & & & \\
4.2 & & & 5.7 & & \\
4.3 & & & 8.5 & & \\
4.4 & & & 11.5 & 0.2 & \\
4.5 & & & & 2.1 & \\
4.6 & & & & 3.0 & \\
4.7 & & & 4.2 & 0.1 \\
4.8 & & & & & 0.2 \\
4.9 & & & & & 0.6 \\
5.0 & & & & & 0.2 \\
\hline
\end{tabular}

with aniline. The higher molecular weight homologues, such as compounds $15(\mathrm{~m} / \mathrm{z} 420), 19(\mathrm{~m} / \mathrm{z} 496), 23(\mathrm{~m} / \mathrm{z}$ 572) and $24(\mathrm{~m} / \mathrm{z} 586)$, are also weak in samples 1 and 2. The structures for compounds $\mathbf{1 2}, \mathbf{1 3}, \mathbf{1 6}, \mathbf{1 7}$ and $\mathbf{2 1}$ are suggested because the primary amines of rosaniline, or a substituted rosaniline, will be more reactive and will condense
Table 14. Group 3 in Figure 9.

\begin{tabular}{llllll}
\hline Min/m/z & 440 & 454 & 468 & 482 & 496 \\
\hline 5.2 & 2.6 & & & & \\
5.4 & & 1.3 & & & \\
5.5 & & 4.2 & & & \\
5.6 & & & 0.3 & & \\
5.7 & & & 1.7 & & \\
5.8 & & & 2.2 & 0.4 & \\
6.0 & & & & 0.7 & \\
5.9 & & & & & 0.0 \\
6.1 & & & & 0.3 & 0.1 \\
6.2 & & & & & 0.1 \\
\hline
\end{tabular}

Table 15. Group 4 in Figure 9.

\begin{tabular}{llllll}
\hline $\mathrm{Min} / \mathrm{m} / \mathrm{z}$ & 516 & 530 & 558 & 572 & 586 \\
\hline 6.3 & 0.5 & & & & \\
6.5 & & 1.2 & & & \\
6.8 & & & 0.1 & & \\
6.9 & & & 0.2 & & \\
7.0 & & & & 0.1 & \\
7.1 & & & & & 0.0 \\
\hline
\end{tabular}

more rapidly with aniline than those primary amines, which have an ortho methyl group hindering them.

\section{Conclusion}

LC-MS analysis of the mauveine sample in the historical archive of the Technical University of Dresden shows that it contains mainly mauveine A and a monomethyl mauveine chromophore. According to the records, this mauveine was 
Table 16. Four groups of dyes made from rosaniline with either none, one, two or three arylamines showing the proposed structures, formulae, and measured and calculated accurate masses \{\}$\cdot{ }^{31}$.

\begin{tabular}{|c|c|c|c|c|c|}
\hline No. & Dye & Formulae & Molecular weight & {$[\mathrm{M}]+$} & $\Delta \mathrm{ppm}$ \\
\hline \multicolumn{6}{|c|}{ Group I } \\
\hline 2 & & $\mathrm{C}_{19} \mathrm{H}_{18} \mathrm{~N}_{3}$ & 288 & $\begin{array}{l}288.1495\{288.1495\} \\
13 \mathrm{rdb}\end{array}$ & 0.1 \\
\hline 8 & & $\mathrm{C}_{20} \mathrm{H}_{20} \mathrm{~N}_{3}$ & 302 & $\begin{array}{l}302.1650\{302.1652\} \\
13 \mathrm{rdb}\end{array}$ & 0.4 \\
\hline 9 & & $\mathrm{C}_{21} \mathrm{H}_{22} \mathrm{~N}_{3}$ & 316 & $\begin{array}{l}316.1807\{3 \mid 6.1808\} \\
13 \mathrm{rdb}\end{array}$ & 0.3 \\
\hline 10 & & $\mathrm{C}_{22} \mathrm{H}_{24} \mathrm{~N}_{3}$ & 330 & $\begin{array}{l}330.1964\{330.1965\} \\
13 \mathrm{rdb}\end{array}$ & 0.3 \\
\hline \multicolumn{6}{|c|}{ Group 2} \\
\hline II & & $\mathrm{C}_{25} \mathrm{H}_{22} \mathrm{~N}_{3}$ & 364 & $\begin{array}{l}364.1807\{364.1808\} \\
17 \mathrm{rdb}\end{array}$ & 0.3 \\
\hline 12 & & $\mathrm{C}_{26} \mathrm{H}_{24} \mathrm{~N}_{3}$ & 378 & $\begin{array}{l}378.1963\{378.1965\} \\
17 \mathrm{rdb}\end{array}$ & 0.4 \\
\hline 13 & & $\mathrm{C}_{27} \mathrm{H}_{26} \mathrm{~N}_{3}$ & 392 & $\begin{array}{l}392.2120\{392.2121\} \\
17 \mathrm{rdb}\end{array}$ & 0.3 \\
\hline 14 & & $\mathrm{C}_{28} \mathrm{H}_{28} \mathrm{~N}_{3}$ & 406 & $\begin{array}{l}406.227\{406.2278\} \\
17 \mathrm{rdb}\end{array}$ & 0.3 \\
\hline 15 & & $\mathrm{C}_{29} \mathrm{H}_{30} \mathrm{~N}_{3}$ & 420 & $\begin{array}{l}420.2433\{420.2434\} \\
17 \mathrm{rdb}\end{array}$ & -0.1 \\
\hline \multicolumn{6}{|c|}{ Group 3} \\
\hline 3 & & $\mathrm{C}_{31} \mathrm{H}_{26} \mathrm{~N}_{3}$ & 440 & $\begin{array}{l}440.2121\{440.2121\} \\
21 \mathrm{rdb}\end{array}$ & 0.1 \\
\hline 16 & & $\mathrm{C}_{32} \mathrm{H}_{28} \mathrm{~N}_{3}$ & 454 & $\begin{array}{l}454.2277\{454.2278\} \\
21 \mathrm{rdb}\end{array}$ & 0.2 \\
\hline
\end{tabular}


Table 16. (Continued)

\begin{tabular}{|c|c|c|c|c|c|}
\hline No. & Dye & Formulae & Molecular weight & {$[\mathrm{M}]+$} & $\Delta \mathrm{ppm}$ \\
\hline 17 & & $\mathrm{C}_{33} \mathrm{H}_{30} \mathrm{~N}_{3}$ & 468 & $\begin{array}{l}468.2433\{468.2334\} \\
21 \mathrm{rdb}\end{array}$ & 0.2 \\
\hline 18 & & $\mathrm{C}_{34} \mathrm{H}_{32} \mathrm{~N}_{3}$ & 482 & $\begin{array}{l}482.2590\{482.2591\} \\
21 \mathrm{rdb}\end{array}$ & 0.2 \\
\hline 19 & & $\mathrm{C}_{35} \mathrm{H}_{34} \mathrm{~N}_{3}$ & 496 & $\begin{array}{l}496.2746\{496.2747\} \\
21 \mathrm{rdb}\end{array}$ & 0.3 \\
\hline \multicolumn{6}{|c|}{ Group 4} \\
\hline 20 & & $\mathrm{C}_{37} \mathrm{H}_{30} \mathrm{~N}_{3}$ & 516 & $\begin{array}{l}516.2434\{516.2434\} \\
25 \mathrm{rdb}\end{array}$ & 0.1 \\
\hline 21 & & $\mathrm{C}_{38} \mathrm{H}_{32} \mathrm{~N}_{3}$ & 530 & $\begin{array}{l}530.2590\{530.2591\} \\
25 \mathrm{rdb}\end{array}$ & 0.1 \\
\hline 22 & & $\mathrm{C}_{40} \mathrm{H}_{36} \mathrm{~N}_{3}$ & 558 & $\begin{array}{l}558.2903\{558.2904\} \\
25 \mathrm{rdb}\end{array}$ & 0.1 \\
\hline 23 & & $\mathrm{C}_{41} \mathrm{H}_{38} \mathrm{~N}_{3}$ & 572 & $\begin{array}{l}572.3058\{572.3060\} \\
25 \mathrm{rdb}\end{array}$ & 0.3 \\
\hline 24 & & $\mathrm{C}_{42} \mathrm{H}_{40} \mathrm{~N}_{3}$ & 586 & $\begin{array}{l}586.32 \mid 8\{586.32 \mid 7\} \\
25 \mathrm{rdb}\end{array}$ & -0.2 \\
\hline
\end{tabular}

rdb: rings plus double bonds. $\Delta \mathrm{ppm}$ refers to the accuracy of the accurate mass measurement.

given to the collection by W. H. Perkin in the 19th century. The synthesis might be following Perkin' ${ }^{2}$ patented procedure with an increased toluidine content in the aniline, or by modifying a unique process we introduced to explain the composition of Perkin's mauveine stored in museums which is rich in mauveine A and B. ${ }^{16,26}$ Perkin's original 1856 method would be expected to give both mauveine A and B and other mauveine chromophores. ${ }^{17-19}$ This is the first sample of mauveine attributed to Perkin which is not a characteristic composition of mauveine $\mathrm{A}$ and $\mathrm{B}$ found in a number 
of museums. ${ }^{13,20-24}$ It suggests the possibility that mauveine used for some of the rare plate 6 Victorian $6 \mathrm{~d}$ stamps might have come from Perkin's, and not just Caro's, factory. ${ }^{27,30}$ Three samples of phenylated rosanilines have been analysed by LC-MS. The method works well for cationic aniline dyes. Samples 1 and 2 are similar and show a complex mixture of products consisting of some starting material (rosaniline or fuchsin), monophenylated, diphenylated and triphenylated rosanilines. Each group is a mixture because the rosaniline starting material, which aniline reacted with,

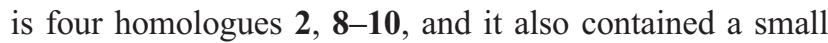
amount of toluidine. LC-MS is an effective method to separate and analyse these complex mixtures. Their retention time is like mauveine and typical for a cationic aniline dye. Two blue colours form, which would allow control of the commercial blue shade. ${ }^{5}$

\section{Experimental}

For analytical separation, an Agilent 1290 Infinity HPLC system consisting of a quaternary HPLC pump, cooled auto sampler compartment, column compartment and diodearray UV-Vis detector was used. A Gold C-18 column $(2.1 \mathrm{~mm} \times 150 \mathrm{~mm}$, Thermo Scientific, UK) was used for separation with a water/methanol gradient (both $0.1 \% \mathrm{v} / \mathrm{v}$ formic acid) from $40 \%$ to $100 \% \mathrm{MeOH}$ in $7 \mathrm{~min}$. The flow rate was $0.5 \mathrm{mLmin}^{-1}$, column temperature $40^{\circ} \mathrm{C}$ and sample volume $5 \mu \mathrm{L}$. The mass spectrometer (ES-MS) used was a MAXIS II Ultra-High Resolution Time-Of- Flight (UHRTOF) LC-MS System (Bruker UK Ltd, England) with Electro Spray Ionisation (ESI) source connected to the UV-Vis detector by a short length of Poly Ether Ether Ketone (PEEK) tubing. The ES-MS was operated in positive ion mode with a capillary voltage of $4.5 \mathrm{kV}$ using sodium formate clusters for calibration and methyl stearate as lock mass. Mass spectra were recorded automatically.

\section{Sample preparation}

Samples of four dyes were provided in small plastic bags. These were cut open with scissors, and a grain or two of dye was removed with a spatula and placed in a small sample vial $(2 \mathrm{~cm} \times 4 \mathrm{~cm})$. The spatula was cleaned each time to avoid cross-contamination. The grains were dissolved in $\mathrm{MeOH}$ and sent for analysis in a sealed sample vial. Mauveine was supplied in a sample vial.

\section{Acknowledgements}

We are grateful to Prof. Dr. Horst Hartmann of the Historische Farbstoffsammlung, Technische Universität Dresden and to the Chandler museum, New York, for samples to analyse.

\section{Declaration of conflicting interests}

The author(s) declared no potential conflicts of interest with respect to the research, authorship, and/or publication of this article.

\section{Funding}

The author(s) received no financial support for the research, authorship, and/or publication of this article.

\section{ORCID iD}

Michael John Plater (iD https://orcid.org/0000-0003-0204-9695

\section{Supplemental Material}

Supplemental material for this article is available online.

\section{References}

1. Historical Collection of Dyes at the Faculty of Chemistry and Food Chemistry at the Technical University of Dresden, https://tu-dresden.de/mn/chemie/die-fakultaet/farbstoffsammlung/geschichte-der-farbstoffsammlung?set_ language $=$ en

2. Perkin WH. GB 1984, 26 August 1856.

3. Brooman AR. GB 921, 12 April 1859.

4. Girard CA. GB 97, 12 January 1861.

5. Perkin WH. J Chem Soc 1896; 69: 596.

6. Gardner WM. The British coal tar industry: its origin, development and decline. Philadelphia, PA: J. B. Lippincott Company, 1915.

7. Hofmann AW. Compt Rend 1863; 57: 25.

8. Perkin WH. GB 2492, 1 November 1859.

9. Medlock H. GB 126, 18 January 1860.

10. Nicholson EC. GB 184, 25 January 1860.

11. Girard CA and de Laire G. GB 1300, 26 May 1860.

12. Nicholson EC. GB 1857, 24 June 1862.

13. Chandler Museum, Department of Chemistry, Columbia University, New York.

14. American Chemical Society Perkin Medal, https:// en.wikipedia.org/wiki/Perkin_Medal

15. Plater MJ and Raab A. J Chem Res 2017; 41: 441

16. Plater MJ and Raab A. J Chem Res 2018; 42: 589.

17. Meth-Cohn O and Smith M. J Chem Soc Perkin Trans I 1994; 5.

18. Seixas de Melo J, Takato S, Sousa M, et al. Chem Commun $2007 ; 2624$.

19. Sousa MM, Melo MJ, Parola AJ, et al. Chem Eur J 2008; 14: 8507.

20. Science Museum, London.

21. Blythe House Archive, London.

22. Manchester Museum of Science and Industry, Manchester.

23. Colour Experience Museum, Bradford.

24. Brent Museum and Archives, London.

25. Research Outreach. The mystery of the purple Victorian dye, https://researchoutreach.org/articles/mystery-victorian-purple-dye/

26. Plater MJ and Raab A. J Chem Res 2019; 43: 367.

27. Plater MJ and Raab A. J Chem Res 2016; 40: 648.

28. Plater MJ and Raab A. J Chem Res 2015; 39: 180.

29. Dale J and Caro H. GB 1307, 26 May 1860.

30. Oliveira MC, Dias A, Douglas P, et al. Chem Eur 2014; 20 : 1808.

31. Fox MR. Dye-makers of Great Britain 1856-1976: a history of chemists, companies, products and changes. London: Imperial Chemical Industries PLC, 1987.

32. IARC Monograph. Chemical agents and related occupations (Magenta and magenta production). Lyon: International Agency for Research on Cancer, 2012.

33. Nicholson EC. GB 147, 20 January 1862.

34. de Laire G, Girard CA and Chapoteaut P. Liebigs Ann Chem 1866; 140: 344.

35. de Laire G, Girard CA and Chapoteaut P. Compt Rend 1866; 63: 91.

36. Plater MJ. J Chem Res 2011; 35: 304. 